\title{
ChemComm
}

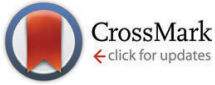

Cite this: Chem. Commun., 2015, 51, 2972

Received 15th December 2014, Accepted 9th January 2015

DOI: $10.1039 / \mathrm{c} 4 \mathrm{cc} 09986 a$

www.rsc.org/chemcomm

\section{Immobilization of polyoxometalates in the Zr-based metal organic framework UiO-67†}

\author{
William Salomon, ${ }^{a}$ Catherine Roch-Marchal, ${ }^{\star a}$ Pierre Mialane, ${ }^{a}$ Paul Rouschmeyer, ${ }^{a}$ \\ Christian Serre, ${ }^{a}$ Mohamed Haouas, ${ }^{a}$ Francis Taulelle, ${ }^{a}$ Shu Yang, \\ Laurent Ruhlmann ${ }^{\mathrm{b}}$ and Anne Dolbecq*a
}

The encapsulation of polyoxometalates within the large pores of the Zr(Iv) biphenyldicarboxylate UiO-67 metal-organic framework has been achieved, for the first time, by direct solvothermal synthesis. The resulting POMaUiO-67 composite materials were fully characterized by XRPD, IR, MAS NMR, $\mathrm{N}_{2}$ porosimetry measurements and cyclic voltammetry.

Polyoxometalates (POMs) are soluble early-transition-metal clusters with a large diversity of structures and compositions. ${ }^{1}$ They possess redox and acid-base properties which can be exploited for catalytic applications. ${ }^{2}$ However their low specific surface area, low stability under catalytic conditions and high solubility in aqueous solution constitute some of their drawbacks. The search for stable heterogeneous catalysts with a high surface area, which could combine the activity of the POMs with the advantages of heterogeneous catalysts, such as easier recovery and recycling, thus attracts a lot of interest. Encapsulation of POMs within the cavities of metal organic frameworks (MOFs) ${ }^{3}$ constitutes a strategy to access to POMs-based heterogeneous catalysts. ${ }^{4}$ The mesoporous M(III)-trimesate MIL-100 and -terephthalate MIL-101 families $(\mathrm{M}=\mathrm{Fe}, \mathrm{Cr}, \mathrm{Al}$; MIL stands for Material of Institut Lavoisier) have been the most investigated host matrices so far because of their very large pore sizes and surface areas and good chemical stability. Keggin-type as well as sandwich-type POMs have been incorporated either by impregnation or in situ during the MOF synthesis. ${ }^{5}$ Besides the MIL families, Cu-BTC frameworks (BTC $=1,3,5$-benzene-tricarboxylate), known as HKUST-1 (HKUST stands for Hong-Kong University of Science and Technology), have been the subject of intense research. ${ }^{5}$ Due to the small size of the pores they can only accommodate

\footnotetext{
${ }^{a}$ Institut Lavoisier de Versailles, UMR 8180, Université de Versailles Saint-Quentin en Yvelines, 45 Avenue des Etats-Unis, 78035 Versailles cedex, France.

E-mail: catherine.roch@uvsq.fr, anne.dolbecq@uvsq.fr

${ }^{b}$ Université de Strasbourg, Institut de Chimie, UMR CNRS 7177, Laboratoire

d'Electrochimie et de Chimie Physique du Corps Solide, 4 rue Blaise Pascal, CS 90032, 67081 Strasbourg cedex, France

$\dagger$ Electronic supplementary information (ESI) available: Detailed syntheses and characterizations. See DOI: $10.1039 / \mathrm{c} 4 \mathrm{cc} 09986 \mathrm{a}$
}

Keggin anions by direct synthesis. However the poor aqueous stability of these copper carboxylate based MOFs might prevent their practical use. Among the few examples of a series of thermally, and chemically stable MOFs with high surface area, the UiO-66 to 68 family (UiO stands for University of Oslo), built up from $\left\{\mathrm{Zr}_{6}{ }_{6} \mathrm{O}_{4}(\mathrm{OH})_{4}\right\}$ oxocluster nodes and linear dicarboxylate linkers (with the general formulae $\left[\mathrm{Zr}_{6}{ }_{6} \mathrm{O}_{4}(\mathrm{OH})_{4}(\text { linker) })_{6}\right]$ ), is one of the most studied MOFs. ${ }^{6}$ These materials exhibit by themselves very promising catalytic properties. ${ }^{7}$ In UiO-67 the inorganic octahedral $\mathrm{Zr}_{6}$ units are bound to 12 other inorganic subunits through biphenyl dicarboxylate ligands forming a face-centered cubic (fcc) structure $(a=27.1 \AA$ ) . This MOF exhibits two types of cages: supertetrahedral $(\varnothing \sim 11.5 \AA)$ and superoctahedral $(\varnothing \sim 18 \AA)$ accessible through microporous triangular windows $(\varnothing \sim 8 \AA$ ) (Fig. 1a), corresponding to the voids of the fcc packing. However, the incorporation of guest molecules within the pores of UiO MOFs has only been rarely studied $^{8}$ and, to our knowledge, there have been so far no reports of POM@UiO composites. Here we propose for the first time a synthetic method for the encapsulation within the pores of UiO-67

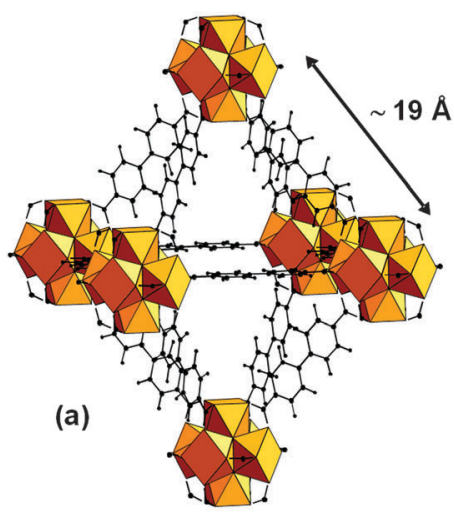

(b)

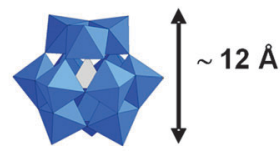

(c)

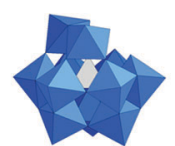

(d)

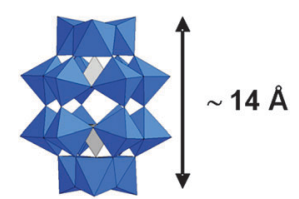

Fig. 1 Polyhedral representations of (a) the octahedral cages of UiO-67, (b) $\left[\mathrm{PW}_{12} \mathrm{O}_{40}\right]^{3-}\left(\mathrm{PW}_{12}\right),\left(\right.$ c) $\left[\mathrm{PW}_{11} \mathrm{O}_{39}\right]^{7-}\left(\mathrm{PW}_{11}\right)$ and (d) $\left[\mathrm{P}_{2} \mathrm{~W}_{18} \mathrm{O}_{62}\right]^{6-}\left(\mathrm{P}_{2} \mathrm{~W}_{18}\right)$; blue octahedra: $\mathrm{WO}_{6}$, grey tetrahedra: $\mathrm{PO}_{4}$, orange polyhedra: $\mathrm{ZrO}_{8}$, black spheres: C, small black spheres: $\mathrm{H}$. 
of three representative examples of POMs: $\left[\mathrm{PW}_{12} \mathrm{O}_{40}\right]^{3-},\left[\mathrm{PW}_{11} \mathrm{O}_{39}\right]^{7-}$ and $\left[\mathrm{P}_{2} \mathrm{~W}_{18} \mathrm{O}_{62}\right]^{6-}$ whose size (Fig. 1b-d) can fit in the microporous octahedral cavities of this MOF.

Attempts to incorporate POMs in the UiO-67 by an impregnation method, like for the MIL-101 materials, ${ }^{5}$ have failed. This can be related to the narrow size of the windows. Thus a direct synthesis approach has been considered. A mixture of the pre-formed POM species $\left(\mathrm{H}_{3}\left[\mathrm{PW}_{12} \mathrm{O}_{40}\right], \mathrm{TBA}_{4} \mathrm{H}_{3}\left[\mathrm{PW}_{11} \mathrm{O}_{39}\right]\right.$ or $\left.\mathrm{TBA}_{6}\left[\mathrm{P}_{2} \mathrm{~W}_{18} \mathrm{O}_{62}\right]\right)$, zirconium tetrachloride, benzoic acid as a modulator, ${ }^{9}$ and biphenyldicarboxylic acid was heated at $120{ }^{\circ} \mathrm{C}$ in dimethylformamide (DMF) (ESI $\dagger$ ). Concentrated $\mathrm{HCl}$ was also added following previous reports. ${ }^{6, d}$ One would also expect that under the synthetic conditions used for the synthesis of UiO-67, the monolacunary $\mathrm{PW}_{11}$ POM would react with $\operatorname{Zr}(\mathrm{Iv})$ ions to lead to the monomeric 1:1 complex $\left[\mathrm{PW}_{11} \mathrm{O}_{39} \mathrm{Zr}\left(\mathrm{H}_{2} \mathrm{O}\right)_{n}\right]^{3-}(n=2,3)$, postulated by Kholdeeva et al. $^{10}$ Such a monomeric monosubstituted complex has also been evidenced in the Dawson ${ }^{11}$ and Lindquist family. ${ }^{12}$ The resulting insoluble microcrystalline materials, $\mathrm{PW}_{12} @$ UiO-67, PW $_{11} \mathrm{Zr} @ U i \mathrm{O}-67$ and $\mathrm{P}_{2} \mathrm{~W}_{18} @$ @UiO-67, respectively, were filtered and washed several times with DMF and acetone. Infrared (IR) spectra (Fig. 2) indicate the presence of both the POM and the MOF, with $\mathrm{P}-\mathrm{O}$ and $\mathrm{W}-\mathrm{O}$ vibration bands characteristic of the POM observed between 850 and $1100 \mathrm{~cm}^{-1}$ together with the carboxylate vibration bands of the linker between 1300 and $1600 \mathrm{~cm}^{-1}$. The positions of the Bragg peaks are similar in the X-ray powder diffraction pattern of bare UiO-67 and of the POM@UiO-67 materials, confirming that the introduction of POMs in the synthetic medium does not perturb the formation of the MOF (Fig. S1, ESI $\dagger$ ).

Elemental analysis combined with thermogravimetric analysis (TGA) measurements allows proposing the $\left[\mathrm{Zr}_{6} \mathrm{O}_{4}(\mathrm{OH})_{5.4}\right]\left[\mathrm{C}_{14} \mathrm{H}_{8} \mathrm{O}_{4}\right]_{5.3}$ formula for UiO-67, in agreement with the existence of linker defects occupied by hydroxide anions. ${ }^{6 b}$ One expects that for

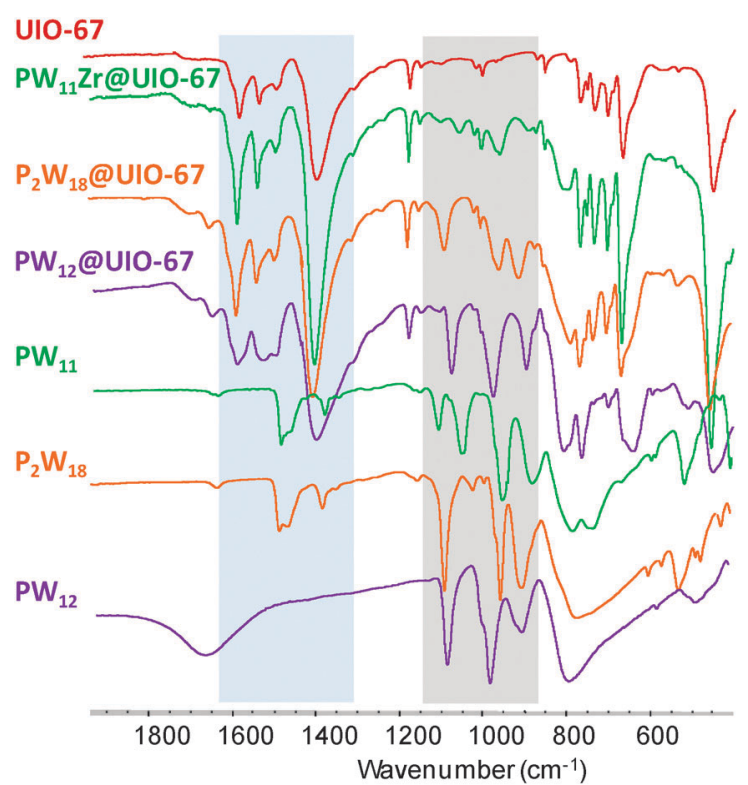

Fig. 2 IR spectra of POMaUiO-67 composites compared to that of the POM precursors and $\mathrm{UiO}-67$. The regions with characteristic peaks of the POMs and of the MOF are highlighted in grey and light blue respectively. the POM@UiO-67 composites, the negative charges introduced by the POMs compensate, almost totally, the linker deficiencies. Note that the presence of tetrabutylammonium cations can be ruled out both by IR, elemental analysis and nuclear magnetic resonance (NMR). The TGA curves for UiO-67 and its composites (Fig. S2 and Table S1, ESI $\dagger$ ) reveal steps that are attributed to water removal, linker decomposition and formation of inorganic oxides. Combined with elemental analyses, these results lead to the estimation of the following formulae $\left[\mathrm{Zr}_{6} \mathrm{O}_{4}(\mathrm{OH})_{4}\right]\left[\mathrm{C}_{14} \mathrm{H}_{8} \mathrm{O}_{4}\right]_{5.37}\left[\mathrm{PW}_{12} \mathrm{O}_{40}\right]_{0.42}\left(\mathrm{PW}_{12} @\right.$ @UiO-67), $\left[\mathrm{Zr}_{6} \mathrm{O}_{4}(\mathrm{OH})_{4}\right]-$ $\left[\mathrm{C}_{14} \mathrm{H}_{8} \mathrm{O}_{4}\right]_{5.73}\left[\mathrm{PW}_{11} \mathrm{O}_{39} \mathrm{Zr}\right]_{0.18}\left(\mathrm{PW}_{11} \mathrm{Zr} @ U i \mathrm{O}-67\right)$, and $\left[\mathrm{Zr}_{6} \mathrm{O}_{4}(\mathrm{OH})_{4.30}\right]$ $\left[\mathrm{C}_{14} \mathrm{H}_{8} \mathrm{O}_{4}\right]_{5.10}\left[\mathrm{P}_{2} \mathrm{~W}_{18} \mathrm{O}_{62}\right]_{0.25}\left(\mathrm{P}_{2} \mathrm{~W}_{18} @ U\right.$ UiO-67) for the POM@UiO-67 composites. As there is one octahedral cavity per $\mathrm{Zr}_{6}$ unit, these formulae indicate that approximately $1 / 2,1 / 5$ and $1 / 4$ of the cavities are occupied by POMs in PW PW $_{12} @$ UiO-67, PW Pr1 $_{11} \mathrm{Zr}$ UiO-67 and $\mathrm{P}_{2} \mathrm{~W}_{18} @$ UiO-67, respectively.

$\mathrm{N}_{2}$ sorption isotherms have been recorded for all the reported compounds (Fig. S3 and Table S2, ESI $\dagger$ ). As expected, the surface area as well as the total pore volumes decrease from UiO-67 to POM@UiO-67 composites, as a consequence of the encapsulation of the POMs within the octahedral cavities, leaving however a significant porosity accessible to nitrogen. It should be noted that the values of the normalized specific surface area, taking into account the mass of UiO-67 in the composites samples, are significantly different from the value of UiO-67 (Fig. S3 and Table S2, ESI $\dagger$ ), suggesting that the POMs are located inside the cavities and not at the surface of the material.

The ${ }^{1} \mathrm{H}$ MAS and ${ }^{13} \mathrm{C}\left\{{ }^{1} \mathrm{H}\right\}$ CPMAS NMR spectra of the three POM@UiO-67 (Fig. S4 and S5, ESI $\dagger$ ) exhibit the characteristic resonances from the crystalline UiO-67. The $\mathrm{Zr}-\mathrm{OH}$ hydroxyl protons from the hexameric unit lie in the $0-3.6 \mathrm{ppm}$ range while the resonances of the linker, i.e. aromatic protons, are observed at 7.1 and $7.9 \mathrm{ppm}$. The aromatic carbon atoms $(125,130$, 134 , and $143 \mathrm{ppm}$ ) and the carbon atoms of the carboxylic function $(172 \mathrm{ppm})$ are in the expected range. ${ }^{8 c}$ Noteworthily, broad components of all these resonances are observed and the general tendency showed that higher the amount of encapsulated POM larger the fraction of these broad resonances (23\% in $\mathrm{PW}_{11} \mathrm{Zr} @ U i \mathrm{U}-67,54 \%$ in $\mathrm{P}_{2} \mathrm{~W}_{18} @$ @UiO-67, and 68\% in $\mathrm{PW}_{12} @$ UiO-67). This is assigned to structural disorder caused by the POM filling pores.

The ${ }^{31} \mathrm{P}$ MAS NMR spectra of $\mathrm{PW}_{12}$ @UiO-67 (Fig. S6a, ESI $\dagger$ ) and $\mathrm{P}_{2} \mathrm{~W}_{18} @$ UiO-67 (Fig. 3a) show characteristic features of the POM precursors with signals at -15.2 and $-12.9 \mathrm{ppm}$ respectively, comparable to the literature values. ${ }^{13}$ In contrast, the spectrum of PW $_{11} \mathrm{Zr} @ U$ UiO-67 (Fig. S7a, ESI + ) exhibits a resonance at -13.2 ppm instead of $-12.4 \mathrm{ppm}$ expected for $\mathrm{PW}_{11}{ }^{14}$ This shift is in perfect agreement with that determined for a mixture of $\mathrm{PW}_{11}$ and $\mathrm{ZrCl}_{4}$ in DMF (Fig. S8, ESI $\dagger$ ).

${ }^{31} \mathrm{P}$ NMR provides not only information about the structure of the POM but also some insights on location and host-guest interactions between the POM and the MOF. Indeed, the ${ }^{1} \mathrm{H}^{-31} \mathrm{P}$ HETCOR (heteronuclear correlation) experiment enables us to probe the dipolar contact between the ${ }^{31} \mathrm{P}$ and ${ }^{1} \mathrm{H}$ nuclei. Correlations between the phosphorus atom of the POM and protons of the aromatic linkers as well as $\mathrm{Zr}-\mathrm{OH}$ framework hydroxyl groups are observed in the three POM@UiO-67 composite materials. This unambiguously indicates the close proximity of the POM 

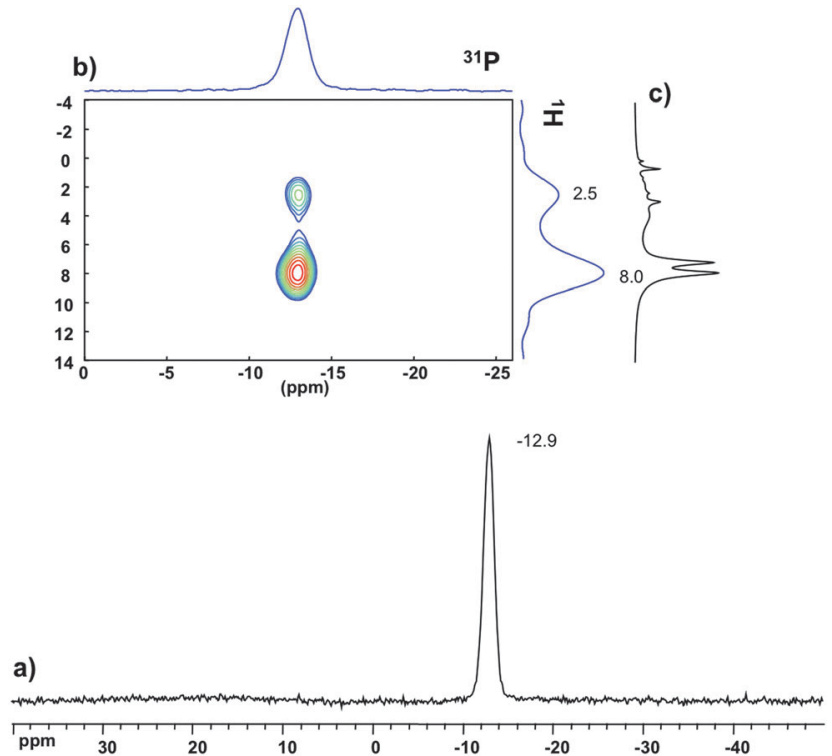

Fig. 3 Solid-state NMR spectra of $\mathrm{P}_{2} \mathrm{~W}_{18}$ (aUiO-67: (a) ${ }^{31} \mathrm{P}\left\{{ }^{1} \mathrm{H}\right\}$ CPMAS; (b) ${ }^{1} \mathrm{H}-{ }^{31} \mathrm{P}$ HETCOR; (c) ${ }^{1} \mathrm{H}$ MAS.

to the surface of the MOF inside the pores homogeneously as otherwise no such efficient dipolar transfer would be seen. Furthermore, the strength of the correlation with these protons appears varied from one POM to another. Indeed in $\mathrm{P}_{2} \mathrm{~W}_{18}$ @UiO-67 (Fig. 3b) and $\mathrm{PW}_{12} @ U$ UiO-67 (Fig. S6b, ESI $\dagger$ ) the ${ }^{31} \mathrm{P}$ site correlates mainly with the aromatic resonance (8 ppm) while in $\mathrm{PW}_{11} \mathrm{Zr@UiO-67}$ (Fig. S7b, ESI $\dagger$ ) the correlation mainly occurs with the hydroxyl group peak $(2.5 \mathrm{ppm})$. This clearly indicates the preferential interaction of $\mathrm{PW}_{12}$ and $\mathrm{P}_{2} \mathrm{~W}_{18}$ with the organic linker, whereas $\mathrm{PW}_{11} \mathrm{Zr}$ should be closer to the inorganic node, suggesting interactions between the $\mathrm{Zr}(\mathrm{vv})$ ions inserted in the POM lacuna and the $\left\{\mathrm{Zr}_{6}^{\mathrm{IV}}{ }_{6} \mathrm{O}_{4}(\mathrm{OH})_{4}\right\}$ clusters. Finally, these correlations involve only the broad components of the ${ }^{1} \mathrm{H}$ spectra (as it could be compared with 1D MAS in Fig. 3c). This strongly suggests as stated above that the POMs are located in the distorted/disordered domain.

The electrochemical properties of the POM@UiO composite materials were also studied and compared to those of the POMs alone. The solids were first immobilized on the surface of the basal plane of the pyrolytic graphite disk (PG) and their electrochemical responses studied in $\mathrm{pH} 2.5 \mathrm{H}_{2} \mathrm{SO}_{4}-\mathrm{Na}_{2} \mathrm{SO}_{4} 0.5 \mathrm{M}$ buffer solutions. $\mathrm{PW}_{12}$ and $\mathrm{P}_{2} \mathrm{~W}_{18}$ and their related POM@UiO-67 composites exhibit similar redox behaviors related to the $\mathrm{W}^{\mathrm{V} / \mathrm{V}}$ redox couples (Table S3, Fig. S9-S11, ESI $\dagger$ and Fig. 4), showing that when saturated POMs are encapsulated inside the cages they retain their electrochemical properties. It must be noted however that the first reduction process for $\mathrm{P}_{2} \mathrm{~W}_{18}$ is $175 \mathrm{mV}$ higher for $\mathrm{P}_{2} \mathrm{~W}_{18} @$ @iO-67 than for $\mathrm{P}_{2} \mathrm{~W}_{18}$.

In the case of $\mathrm{PW}_{11} \mathrm{Zr} @ U$ UiO-67 the cyclovoltammogram clearly shows the complexation of the monolacunary $\mathrm{PW}_{11}$ with $\mathrm{Zr}(\mathrm{Iv})$ and the formation of $\mathrm{PW}_{11} \mathrm{Zr}$ encapsulated in UiO-67 (Fig. S12 and S13, ESI $\dagger$ ). Indeed, $\mathrm{PW}_{11}$ immobilized on the PG exhibits four successive waves at $-0.450 \mathrm{~V},-0.560 \mathrm{~V},-0.694 \mathrm{~V}$ and $-0.830 \mathrm{~V}$ vs. SCE respectively while only two waves are measured for $\mathrm{PW}_{11} \mathrm{Zr} @ U i \mathrm{U}-67$ at $-0.713 \mathrm{~V}$ and $-0.885 \mathrm{~V}$. It should be noted that the

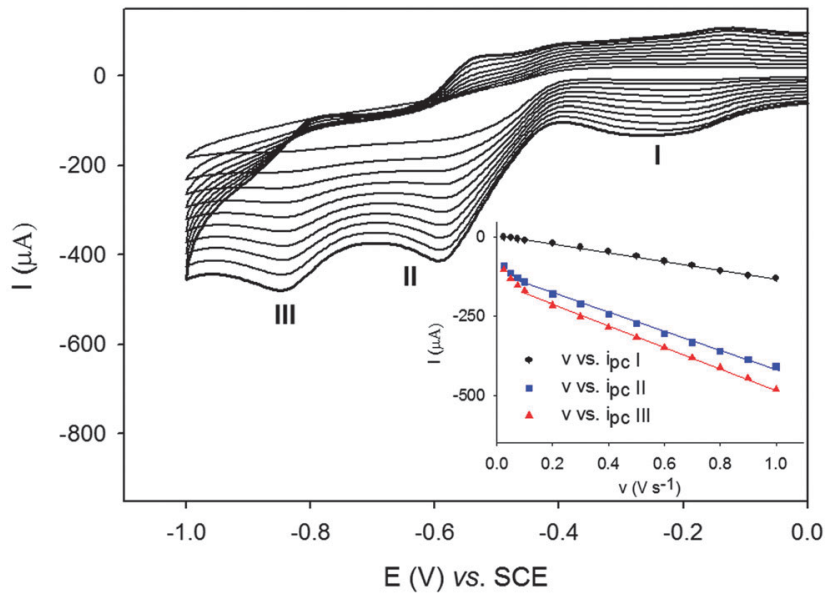

Fig. 4 Cyclic voltammograms of $\mathrm{P}_{2} \mathrm{~W}_{18}$ @UiO-67 immobilized at a PG electrode in a $\mathrm{pH} 2.5 \mathrm{H}_{2} \mathrm{SO}_{4}-\mathrm{Na}_{2} \mathrm{SO}_{4} 0.5 \mathrm{M}$ buffer solution at different scan rates from 0.025 to $1.000 \mathrm{~V} \mathrm{~s}^{-1}$. Inset: plots of $I_{\mathrm{pc}} v s$. $v$ for peaks I, II and III.

electrochemical behaviors of the POM@UiO composites and of composites obtained by mechanical mixing of POMs and UiO (Fig. S14-S16) are different which confirm the encapsulation of the POMs inside the cavities and the transformation of $\mathrm{PW}_{11}$ into $\mathrm{PW}_{11} \mathrm{Zr}$. Finally, all peak current intensities vary linearly with the scan rate in the range $0.1-1.0 \mathrm{~V} \mathrm{~s}^{-1}$, as expected for surface confined redox processes. This behavior is in agreement with the immobilization of the POMs inside the cavities of the MOF and contrasts with the observation of diffusion-controlled processes for $\mathrm{PW}_{11} @ \mathrm{MIL}-101(\mathrm{Cr})$ which were attributed to the mobility of the POMs. ${ }^{15}$

In conclusion, the immobilization of three polyoxotungstates in the largest pores of UiO-67(Zr) has been carried out for the first time, by a direct synthetic method. POM encapsulation compensates almost totally the linker deficiencies. The elaborated POM@UiO-67 composites have been thoroughly characterized. Cyclic voltammetry studies have confirmed the direct formation of $\mathrm{PW}_{11} \mathrm{Zr}$ during the synthetic process and the integrity of the saturated inserted POMs $\mathrm{PW}_{12}$ and $\mathrm{P}_{2} \mathrm{~W}_{18}$. MAS NMR experiments provided essential information on the structure of the composites. First, they have shown interactions between the POMs and the framework, thus confirming the encapsulation within the structure. Moreover they highlighted the existence of disordered domains related to the presence of the POMs. Finally they evidenced specific interactions between the asymmetric $\mathrm{PW}_{11} \mathrm{Zr}$ POMs and the UiO framework. Noticeably, because of the small size of the cage windows, POM leaching cannot occur in these materials. The introduction of POMs might pave the way for future applications in catalysis. It may also greatly influence the hydrophilicity of the materials and thus their gas sorption properties. Future work will focus on these two applications.

This work was supported by CNRS, UVSQ, University of Strasbourg and the French National Research Agency (ANR) as part of the "Investissements d'Avenir" program no. ANR-11IDEX-0003-02 and CHARMMMAT ANR-11-LABX-0039. Patricia Horcajada and Thomas Devic are gratefully acknowledged for fruitful discussions. 


\section{Notes and references}

1 (a) H. N. Miras, L. Vilà-Nadal and L. Cronin, Chem. Soc. Rev., 2014, 43, 5679; (b) O. Oms, A. Dolbecq and P. Mialane, Chem. Soc. Rev., 2012, 41, 7497; (c) A. Proust, B. Matt, R. Villanneau, G. Guillemot, P. Gouzerh and G. Izzet, Chem. Soc. Rev., 2012, 41, 7605.

2 (a) H. Lv, Y. V. Geletii, C. Zhao, J. W. Vickers, G. Zhu, Z. Luo, J. Song, T. Lian, D. G. Musaev and C. L. Hill, Chem. Soc. Rev., 2012, 41, 7572; (b) A. Sartorel, M. Bonchio, S. Campagna and F. Scandola, Chem. Soc. Rev., 2013, 42, 2262; (c) N. Mizuno and K. Kamata, Coord. Chem. Rev., 2011, 255, 2358; (d) X.-B. Han, Z.-M. Zhang, T. Zhang, Y.-G. Li, W. Lin, W. You, Z.-M. Su and E.-B. Wang, J. Am. Chem. Soc., 2014, 136, 5359.

3 Special issue on Metal Organic Frameworks Chem. Soc. Rev., 2014, 43, 5415.

4 J. Juan-Alcañiz, J. Gascon and F. Kapteijn, J. Mater. Chem., 2012, 22, 10102.

5 See for example: (a) N. V. Maksimchuk, M. N. Timofeeva, M. S. Melgunov, A. N. Shmakov, Y. A. Chesalov, D. N. Dybtsev, V. P. Fedin and O. A. Kholdeeva, J. Catal., 2008, 257, 315; (b) L. Bromberg, Y. Diao, H. Wu, S. C. A. Speakman and T. A. Hatton, Chem. Mater., 2012, 24, 1664; (c) C. M. Granadeiro, A. D. S. Barbosa, P. Silva, F. A. Almeida Paz, V. K. Saini, J. Pires, B. de Castro, S. S. Balula and L. Cunha-Silva, Appl. Catal., A, 2013, 453, 316; (d) J. Juan-Alcañiz, E. V. Ramos-Fernandez, U. Lafont, J. Gascon and F. Kapteijn, J. Catal., 2010, 269, 229; (e) A.-X. Yan, S. Yao, Y.-G. Li, Z.-M. Zhang, Y. Lu, W.-L. Chen and E.-B. Wang, Chem. Eur. J., 2014, 20, 6927; $(f)$ S. R. Bajpe, C. E. A. Kirschhock, A. Aerts, E. Breynaert, G. Absillis, T. N. Parac-Vogt, L. Giebeler and J. A. Martens, Chem. - Eur. J., 2010, 16, 3926; (g) J. Song, Z. Luo, D. K. Britt, H. Furukawa, O. M. Yaghi, K. I. Hardcastle and C. L. Hill, J. Am. Chem. Soc., 2011, 133, 16839; (h) J. J.-A. Alcañiz, M. Goesten, A. Martinez-Joaristi, E. Stavitski, A. V. Petukhov, J. Gascon and F. Kapteijn, Chem. Commun, $2011,47,8578$. The complete list of references is given in the $\mathrm{ESI} \dagger$ section.

6 (a) J. H. Cavka, S. Jakobsen, U. Olsbye, N. Guillou, C. Lamberti, S. Bordiga and K. P. Lillerud, J. Am. Chem. Soc., 2008, 130, 13850; (b) M. J. Katz, Z. J. Brown, Y. J. Colón, P. W. Siu, K. A. Scheidt, R. Q. Snurr, J. T. Hupp and O. K. Farha, Chem. Commun., 2013, 49, 9449; (c) J. E. Mondloch, M. J. Katz, N. Planas, D. Semrouni,
L. Gagliardi, J. T. Hupp and O. K. Fahra, Chem. Commun., 2014, 50, 8944; (d) P. S. Barciá, D. Guimarães, P. A. P. Mendes, J. A. C. Silva, V. Guillerm, H. Chevreau, C. Serre and A. E. Rodrigues, Microporous Mesoporous Mater., 2011, 139, 67; (e) G. C. Schearer, S. Chavan, J. Ethiraj, J. G. Vitillo, S. Svelle, U. Olsbye, C. Lamberti, S. Bordiga and K. P. Lillerud, Chem. Mater., 2014, 26, 4068.

7 (a) F. Vermoortele, R. Ameloot, A. Vimont, C. Serre and D. De Vos, Chem. Commun., 2010, 47, 1521; (b) M. J. Katz, J. E. Mondloch, R. K. Totten, J. K. Park, S. T. Nguyen, O. K. Farha and J. T. Hupp, Angew. Chem., Int. Ed., 2014, 53, 497.

8 (a) S. Devautour-Vinot, C. Martineau, S. Diaby, M. Ben-Yahia, S. Miller, C. Serre, P. Horcajada, D. Cunha, F. Taulelle and G. Maurin, J. Phys. Chem. C, 2013, 117, 11694; (b) J. He, J. Wang, Y. Chen, J. Zhang, D. Duan, Y. Wang and Z. Yan, Chem. Commun., 2014, 50, 7063; (c) C. Larabi and E. A. Quadrelli, Eur. J. Inorg. Chem., 2012, 3014.

9 A. Schaate, P. Roy, A. Godt, J. Lippke, F. Waltz, M. Wiebcke and P. Behrens, Chem. - Eur. J., 2011, 17, 6643.

10 O. A. Kholdeeva, G. M. Maksmimov, R. I. Maksimovskaya, M. P. Vanina, T. A. Trubitsina, D. Y. Naumov, B. A. Kolesov, N. S. Antonova, J. J. Carbó and J. M. Poblet, Inorg. Chem., 2006, 45, 7224.

11 (a) M. N. Sokolov, N. V. Izarova, E. V. Peresypkina, D. A. Mainichev and V. P. Fedin, Inorg. Chim. Acta, 2009, 362, 3756; (b) S. Vanhaecht, G. Absillis and T. N. Parac-Vogt, Dalton Trans., 2013, 42, 15437.

12 R. J. Errington, P. S. S. Petkar, P. S. Middleton and W. McFarlane, J. Am. Chem. Soc., 2007, 129, 12181.

13 (a) J. Chunjie, S. Shengnan, W. Xuyang, W. Xiangsheng, G. Hongchen, G. Xinwen and C. Lidong, Acta Chim. Sin., 2013, 71, 810; (b) S. Ribeiro, A. D. S. Barbosa, A. C. Gomes, M. Pillinger, I. S. Gonçalves, L. Cunha-Silva and S. S. Balula, Fuel Process. Technol., 2013, 116, 350.

14 G. Férey, C. Mellot-Draznieks, C. Serre, F. Millange, J. Dutour, S. Surblé and I. Margiolaki, Science, 2005, 309, 2040.

15 P. M. Paes de Sousa, R. Grazina, A. D. S. Barbosa, B. de Castro, J. J. G. Moura, L. Cunha-Silva and S. S. Balula, Electrochim. Acta, 2013, 87, 853. 